\title{
Tissue-Specific Components of Resistance to Aspergillus Ear Rot of Maize
}

\author{
Santiago X. Mideros, Gary L. Windham, W. Paul Williams, and Rebecca J. Nelson
}

First and fourth authors: Department of Plant Pathology and Plant-Microbe Biology, Cornell University, Ithaca, NY 14853; second and third authors: United States Department of Agriculture-Agricultural Research Service, Corn Host Plant Resistance Research Unit, Mississippi State 39762; and fourth author: Department of Plant Breeding and Genetics, Cornell University.

Accepted for publication 30 April 2012.

\begin{abstract}
Mideros, S. X., Windham, G. L., Williams, W. P., and Nelson, R. J. 2012. Tissue-specific components of resistance to Aspergillus ear rot of maize. Phytopathology 102:787-793.

Aspergillus flavus and other Aspergillus spp. infect maize and produce aflatoxins. An important control measure is the use of resistant maize hybrids. There are several reports of maize lines that are resistant to aflatoxin accumulation but the mechanisms of resistance remain unknown. To gain a better understanding of resistance, we dissected the phenotype into 10 components: 4 pertaining to the response of silk, 4 pertaining to the response of developing kernels, and 2 pertaining to the response of mature kernels to inoculation with A. flavus. In order to challenge different

tions on a panel of diverse maize inbred lines over 3 years. As is typical for this trait, significant genotype-environment interactions were found for all the components of resistance studied. There was, however, significant variation in maize germplasm for susceptibility to silk and kernel colonization by A. flavus as measured in field assays. Resistance to silk colonization has not previously been reported. A significant correlation of resistance to aflatoxin accumulation with flowering time and kernel composition traits (fiber, ash, carbohydrate, and seed weight) was detected. In addition, correlation analyses with data available in the literature indicated that lines that flower later in the season tend to be more resistant. We were not able to demonstrate that components identified in vitro were associated with reduced aflatoxin accumulation in the field.
\end{abstract} tissues and to evaluate multiple components of resistance, various inoculation methods were used in experiments in vitro and under field condi-
Additional keywords: quantitative disease resistance, Zea mays.
Aflatoxins are fungal secondary metabolites produced by several species from the genus Aspergillus. Aflatoxin B1 is the most potent naturally occurring carcinogen known (35). In maize (Zea mays L. subsp. mays), the most common causal agent of aflatoxin contamination is Aspergillus flavus Link (teleomorph: Petromyces flavus) (17). Aflatoxin accumulation in maize occurs in the field (preharvest) and in storage (postharvest). Control measures include planting maize lines that are resistant to aflatoxin accumulation, agronomic management to minimize plant stress, moisture management during storage, detoxification, and regulatory enforcement $(16,22)$. Field assessments of resistance show large and significant differences for aflatoxin accumulation in a given trial but the absolute and relative values are inconsistent across trials. Some genotypes have shown relatively consistent resistance or susceptibility $(3,15,36,37)$. However, a high genotype-environment interaction and low heritability are generally recognized for the trait. Weather conditions, particularly temperature and humidity, strongly affect aflatoxin accumulation (40).

The genetic basis of resistance has been studied using diallel crosses and quantitative trait loci (QTL) mapping populations. Early studies indicated the absence of complete resistance and pointed to a strong role for general combining ability, suggesting that the genetic effects are additive. However, specific combining ability was the main effect in some studies, suggesting the

Corresponding author: R. J. Nelson; E-mail address: rjn7@ cornell.edu

* The $\boldsymbol{e}$-Xtra logo stands for "electronic extra" and indicates that the online version contains six supplementary tables.

http://dx.doi.org/10.1094/PHYTO-12-11-0355

(C) 2012 The American Phytopathological Society presence of dominant or epistatic gene effects $(3,7,15,39)$. More recent QTL mapping experiments confirmed the importance of additive genetic effects $(4,33,34)$. No genes have been cloned for resistance to A. flavus using a positional cloning approach. However, transcriptional and proteomic studies have implicated several genes. Of particular interest is PR10, which was silenced using RNAi to confirm its involvement in resistance to aflatoxin accumulation in vitro in mature kernel assays (9).

The mechanisms by which maize plants accumulate lower levels of aflatoxin remain poorly understood. For host-pathogen interactions in general, the pathogenesis process can be divided into the components of infection, colonization, and reproduction. Incomplete or quantitative resistance can affect these processes differentially (24). A few QTL for quantitative plant-disease resistance have been cloned for other pathosystems (31) and many genes have been implicated in resistance through genome-wide association studies $(18,28)$, suggesting that diverse host functions contribute to quantitative disease resistance (27). Microscopic analysis of components of quantitative resistance using nearisogenic maize lines containing two distinct QTL for resistance to Setosphaeria turcica recently revealed that, while one QTL reduced infection efficiency, the other limited colonization (10). For Ustilago maydis, another maize pathogen, different QTL were found to be associated with resistance in various maize tissues (2). Because QTL for quantitative disease resistance can be specific to different stages of pathogenesis and effective in distinct tissues, we hypothesized that the mechanisms underlying quantitative resistance to A. flavus affect different components of resistance, and that some of these components may be tissue specific. We further hypothesized that greater consistency of expression of resistance would be observed for individual components than for overall accumulation of aflatoxin. 
Previous studies suggest several potential mechanisms for resistance to A. flavus in maize. For this pathosystem, infection of the kernels in undamaged maize ears involves entry of $A$. flavus into the ear through the silk channel (30). Although silk resistance to infection by another ear rot pathogen, Fusarium graminearum, has been characterized (29), evidence for silk resistance to $A$. flavus is indirect $(26,40)$. Several authors have pointed out that aflatoxin accumulation may be related to kernel traits such as grain composition or plant traits such as husk cover or pericarp thickness (15). Two studies have found significant correlations between aflatoxin accumulation and traits such as grain texture, husk cover, grain yield, and silk channel length $(1,3)$. In addition, the pericarp wax of a resistant maize line has been shown to reduce the in vitro growth of A. flavus (14). Recently, an analysis of the cob proteome from susceptible and resistant lines suggested that the tissue from resistant lines had more constitutive defense proteins while that from susceptible lines had more induced defense proteins (25). Although forward and reverse genetic studies have implicated several potential mechanisms, we chose to study this resistance by focusing our efforts on the phenotype.

To dissect the highly variable phenotype by looking for resistance at the multiple steps of the plant-fungus interaction, we used a panel of diverse inbred maize lines and evaluated four components of silk resistance, four of developing kernel resistance, and two components of mature kernel resistance in replicated experiments over 3 years. We conducted in vitro and field inoculations with the objective of controlling environmental conditions after pathogen challenge and compared these results with those obtained under field conditions. Because we hypothesized that natural variability exists in maize for colonization in silk and kernel tissues, we directly challenged the two tissues. As measures of resistance or susceptibility, we determined the extent of $A$. flavus colonization by means of a quantitative polymerase chain reaction (PCR) assay, assessed the timing and extent (incidence and severity) of sporulation, and measured aflatoxin accumulation. To determine whether any of the components is a reliable predictor of aflatoxin accumulation under field conditions, we conducted a correlation analysis and included other traits available for this panel of diverse maize lines.

\section{MATERIALS AND METHODS}

Plant and fungal materials. A panel of 25 maize inbred lines (Table 1) was assembled. Lines were chosen because they have been recognized as sources of resistance (Mp717 and CML322) or susceptibility ( $\mathrm{Sc} 212 \mathrm{~m}$ and Mo17) to aflatoxin accumulation or because they were selected by others to maximize their diversity $(3,13,37,38)$. The panel was planted in 2007, 2008, and 2009 at Cornell's Robert Musgrave Research Farm in Aurora, NY (CU) and in 2008, 2009, and 2010 at the R. R. Foil Plant Science Research Center at Mississippi State University (MSU). For a preliminary experiment, seven inbreds were planted in single pots in a greenhouse during winter 2007 in Ithaca, NY.

Inoculum for in vitro procedures was prepared by growing $A$. flavus isolate NRRL 3357 on $20 \mathrm{~g}$ of maize kernels. Prior to inoculation, the maize kernels used as substrate for inoculum production were soaked overnight with $10 \mathrm{ml}$ of $\mathrm{H}_{2} \mathrm{O}$ in $500-\mathrm{ml}$ flasks and then autoclaved. Conidia were washed 12 to 18 days after inoculation with $20 \mathrm{ml}$ of distilled $\mathrm{H}_{2} \mathrm{O}$ containing $0.2 \%$ Tween 20. Conidia concentration was adjusted to $1 \times 10^{7}$ conidia/ml with a hemocytometer.

For field inoculations, A. flavus isolate NRRL 3357 was seeded onto $50 \mathrm{~g}$ of sterile maize cob grits with $100 \mathrm{ml}$ of $\mathrm{H}_{2} \mathrm{O}$ and incubated at $28^{\circ} \mathrm{C}$ for 3 weeks. Conidia were rinsed from the grits and the suspension was filtered through four layers of cheesecloth before adjusting the concentration of the inoculum to $3 \times 10^{8}$ conidia/ml. Ears were inoculated 7 days after $50 \%$ of the silks had emerged.

Components of silk resistance. To produce the test tissues for in vitro inoculation, 12 kernels of each maize line were planted in single rows at CU. Five individual pots were planted for the greenhouse grow-outs. At anthesis, silks of four plants in a row were cut at the tip and the ears were covered with shoot bags. The next day, the newly emerged silks were sib or self pollinated. One day after pollination, the tips of the ears, including the recently pollinated silks, were cut and transported to the laboratory on ice.

For each experimental unit (one plant), 5 silks in 2007 and 10 in 2008 and 2009 were placed in a petri plate without a lid. Dishes were contained in culture trays lined with chromatography

TABLE 1. Least squares means for silk and kernel components of resistance to Aspergillus flavus in a panel of diverse maize inbred lines inoculated for 3 years in the fieldy

\begin{tabular}{|c|c|c|c|}
\hline \multirow[b]{2}{*}{ Line } & \multicolumn{2}{|c|}{ Mature kernel } & \multirow{2}{*}{$\begin{array}{c}\text { Silk } \\
\text { Colonization (IC) }\end{array}$} \\
\hline & Aflatoxin (ng/g) & Colonization (IC) & \\
\hline Mo17 & $6,596 \mathrm{a}$ & $1.63 \mathrm{ab}$ & $0.14 \mathrm{c}$ \\
\hline $\mathrm{Sc} 212 \mathrm{~m}$ & & & $0.07 \mathrm{bc}$ \\
\hline B73 & $4,596 \mathrm{ab}$ & 0.85 bcde & $0.21 \mathrm{c}$ \\
\hline IBM262 & $4,536 \mathrm{ab}$ & 0.69 bcde & $4.37 \mathrm{ab}$ \\
\hline B97 & $3,932 \mathrm{abc}$ & $1.75 \mathrm{a}$ & $0.61 \mathrm{c}$ \\
\hline $\mathrm{Il} 14 \mathrm{H}$ & & & $1.04 \mathrm{bc}$ \\
\hline Мp339 & 1,182 abcdef & $0.64 \mathrm{cde}$ & $0.05 \mathrm{c}$ \\
\hline Ку21 & 1,046 abcdef & $0.91 \mathrm{abcd}$ & $0.69 \mathrm{bc}$ \\
\hline NC350 & 889 abcdef & $\ldots$ & $0.67 \mathrm{bc}$ \\
\hline Тх303 & 874 abcdef & 0.38 cde & $1.77 \mathrm{bc}$ \\
\hline MS71 & 705 bcdef & 0.73 bcde & $0.07 \mathrm{c}$ \\
\hline Ki3 & 268 defg & $0.23 \mathrm{e}$ & $0.81 \mathrm{bc}$ \\
\hline Mp717 & 264 bcdefg $^{z}$ & $\ldots$ & $0.00 \mathrm{c}$ \\
\hline
\end{tabular}

${ }^{y}$ Colonization was determined by quantitative polymerase chain reaction, which produced an infection coefficient (IC) as reported previously (21). Levels not connected by the same letter are significantly different as determined by Tukey's test $(\alpha=0.05)$.

${ }^{\mathrm{z}}$ Line Mp717 was only in 2 years of studies; therefore, it is penalized in the multiple comparison test. 
paper moistened with $30 \mathrm{ml}$ of sterile $\mathrm{H}_{2} \mathrm{O}$ to maintain humidity. Four replicates of each line were prepared from the four plants in a row. Silks were inoculated with $10 \mu \mathrm{l}$ in 2007 and $50 \mu \mathrm{l}$ in 2008 and 2009 of A. flavus conidia prepared as indicated above. After inoculation, culture trays were placed in an incubator at $30^{\circ} \mathrm{C}$ for 7 days in the dark.

For latent period (LP) rating, trays were observed daily under a dissecting microscope until the appearance of the first conidiophore-bearing yellow-green conidia. Sporulation on silks rarely covered the whole silk but differences on the density of sporangia near the inoculation point were observed. In order to capture these differences, the sporulation (SP) rating was conducted 7 days after inoculation with a dissecting microscope, using a scale from 0 to 5 where 0 meant no spores and 5 was the highest density of conidiophores. Infection frequency (IF) was rated as a percentage of the silks infected, determined by the presence of conidiophores. When SP and IF rating were complete, the top $3 \mathrm{~cm}$ of the silks was cut and kept at $-80^{\circ} \mathrm{C}$ until DNA extraction for colonization rating using quantitative PCR (qPCR) as explained below.

Field inoculation was conducted in an environment conducive to aflatoxin accumulation at MSU (high temperature and routinely known high levels of aflatoxin accumulation). Inbred lines were planted in a randomized complete block design with three replicates. Each line was planted in 4-m single-row plots spaced $0.97 \mathrm{~m}$ apart. To measure components of resistance in the silk and in the kernels, both sites were inoculated by injecting $1.7 \mathrm{ml}$ of the conidial suspension into the silk channel and $1.7 \mathrm{ml}$ underneath the husk into the side of the top ear, 7 days after midsilk stage.

To determine the levels of silk colonization, two ears from each row were collected 7 days after inoculation and transported to the laboratory on ice. Approximately $100 \mathrm{mg}$ of silk tissue from the ear channel was collected in 1.2-ml polypropylene Costar cluster tubes (Corning Inc., Corning, NY) and frozen until processing. Silk samples were lyophilized prior to DNA extraction. Colonization levels were determined using TaqMan chemistry qPCR as described previously (21). Briefly, DNA was extracted using a standard cetyltrimethylammonium bromide protocol. Total DNA concentration was determined using Picogreen for all the samples. A. flavus DNA concentration was determined by comparing with a standard curve included in each PCR plate. Three replicates of the qPCR procedure were conducted for each sample. Colonization was calculated by dividing the amount of pathogen DNA by the total DNA for each sample.

Components of kernel resistance. For in vitro inoculation of developing kernels, each inbred planted in the field at CU was self or sib pollinated. At 3 weeks after pollination, a kernel screening assay was conducted (5). Four ears were harvested from each inbred and five developing kernels per ear were placed in small petri plates in culture trays lined with chromatography paper that had been moistened with $30 \mathrm{ml}$ of sterile $\mathrm{H}_{2} \mathrm{O}$. Kernels were dip inoculated in a conidial suspension of A. flavus isolate NRRL 3357 at $1 \times 10^{7}$ conidia/ml, prepared as explained for the silk experiments. The four ears were considered technical replicates for each experiment.

LP was rated every $24 \mathrm{~h}$, by recording the day when the first signs of conidiophore-bearing conidia where visible. IF was visually rated 7 days after inoculation by counting the number of developing kernels visibly infected with $A$. flavus. SP was rated on each kernel 7 days after inoculation using a dissecting microscope as a percentage of the kernel covered with conidiophores. Increments of $1 \%$ were allowed but $5 \%$ differences were the most commonly used. After SP rating, kernels were kept in envelopes at $-80^{\circ} \mathrm{C}$ until processed by $\mathrm{qPCR}$ analysis of $A$. flavus colonization. Kernel samples were lyophilized prior to DNA extraction. Infection levels were determined using TaqMan chemistry qPCR as described previously (21).
Field inoculation for kernel components of resistance was conducted as indicated for the silk experiments at MSU. For aflatoxin determination at harvest, the top ears of each plant in a row were dried at $38^{\circ} \mathrm{C}$ for 7 days. Kernels from each row were ground with a Romer mill (Union, MO), and a subsample was used for aflatoxin measurement using the VICAM AflaTest (Watertown, MA). This same subsample of dried kernels was kept at $4^{\circ} \mathrm{C}$ until processed to determine the levels of colonization using TaqMan chemistry qPCR.

Statistical analysis. All statistical analyses were conducted on JMP V 8.0 (SAS Institute, Cary, NC). Each component of resistance was analyzed independently. For all the components of resistance, data were analyzed for the overall study in a mixedeffects model and on a year-by-year basis. The year of the experiment and the replication were the random variables. For the overall analysis (3 years), only lines for which there were data available for at least 2 years were used. The in vitro inoculation experiments with tissue from the greenhouse study were not included in the overall analysis. All pairwise comparisons were conducted using Tukey's test, which is known to protect against high experiment-wise type I error rates (19). In order to standardize the variances, silk LP and SP data were log transformed, whereas IF and colonization data were arcsine square root transformed. Some of the developing kernel assays for LP and IF did not require a statistical analysis because all the kernels had visible sporangia at the same time. SP data on developing kernels was arcsine square root transformed prior to analysis. Finally, data from field inoculations in the kernel for colonization and aflatoxin accumulation were log transformed.

Pairwise correlations among components of resistance were conducted using the least squares means of each component of resistance for the combined 3 years of data and on a year-by-year basis. For comparison purposes, data on aflatoxin accumulation in kernels from field studies were included with the silk data correlations. Two other datasets were included for comparison: kernel traits reported by Flint-Garcia et al. (12) and days to silk (flowering time) reported by Buckler et al. (6). Because most of the germplasm used in this study was included in the panels analyzed by Flint-Garcia et al. (11) and Buckler et al. (6), it was possible to make comparisons across datasets for the majority of the lines analyzed. Least squares entry means for kernel traits from 14 to 16 inbred lines reported by Flint-Garcia et al. (12) and BLUPs for flowering time (days to silk) from 13 to 18 founder lines reported by Buckler et al. (6) were correlated to our components of kernel resistance. In addition, the BLUPs for flowering time from 12 to 15 founder lines from Buckler et al. (6) were correlated to our components of silk resistance. The least square entry means for kernel traits were calculated from materials grown for 2 years in Puerto Rico (12). The BLUPs for flowering time were calculated from data generated through phenotypic evaluation over 2 years at four locations (6).

\section{RESULTS}

A wide range of aflatoxin accumulation was found in our panel of maize lines (Table 1). Analyzed over the 3 years of field inoculation assays, three tissue-specific components of resistance were significant: A. flavus colonization on silks, A. flavus colonization of mature kernels, as well as aflatoxin accumulation in mature kernels (Tables 1 and 2). All of the components of resistance measured were highly influenced by the environment, with significant effects for the random variation due to the interaction between year and inbred line.

Components of silk resistance (overall analyses). The maize lines in this study differed significantly for the susceptibility of silks to colonization by A. flavus in field inoculation experiments (Table 2). In vitro IF and SP means were significantly correlated (Table 3). None of the components of silk 
resistance correlated with aflatoxin accumulation or with flowering time (days to silk).

Components of kernel resistance (overall analyses). At maturity in field inoculation experiments, we found significant differences in the panel of maize lines for colonization and aflatoxin accumulation (Tables 1 and 2). Aflatoxin levels and colonization were significantly correlated $(0.70, P=0.0008)$ (Table 4). The results of in vitro inoculation of developing kernels were consistent within a year but were highly influenced by the environment in which the mother plants had been grown. The interaction between year and inbred was the dominant source of variation, rendering differences between lines insignificant in the overall analysis (Table 2). There was a significant negative correlation between flowering time (days to silk) and aflatoxin accumulation in the field, as well as between flowering time and in vitro SP of developing kernels (Table 4). Comparing aflatoxin accumulation with previously reported values for kernel traits, aflatoxin was negatively correlated with fiber and ash in kernels, whereas a positive correlation was found between aflatoxin with carbohydrate and seed weight. In vitro SP on developing kernels was negatively correlated with moisture levels of mature kernels.

Year-by-year analyses. There were significant differences among inbred lines for 10 of the 14 experiments on components of silk resistance studied with in vitro inoculation (Table 5). For two of them (LP for field-grown material in 2007 and SP from greenhouse-grown materials in 2007), significant differences were found in the analysis of variance but the differences among inbred

TABLE 2. Estimates of significance ( $P$ values for analysis of variance) for components of resistance to Aspergillus flavus of a set of diverse maize inbred lines over 3 years $^{\mathrm{x}}$

\begin{tabular}{lccc}
\hline & \multicolumn{3}{c}{ Maize tissue $^{\mathrm{z}}$} \\
\cline { 2 - 4 } Component of resistance $^{\mathrm{y}}$ & Silk & $\begin{array}{c}\text { Developing } \\
\text { kernel }\end{array}$ & $\begin{array}{c}\text { Mature } \\
\text { kernel }\end{array}$ \\
\hline In vitro & 0.38 & $\mathrm{~ns}$ & $\ldots$ \\
$\quad$ Latent period & 0.23 & $\mathrm{~ns}$ & $\ldots$ \\
Infection frequency & 0.24 & 0.10 & $\ldots$ \\
Sporulation & $\ldots$ & 0.21 & $\ldots$ \\
$\quad$ Colonization (qPCR) & & & \\
Field & 0.03 & $\ldots$ & 0.03 \\
Colonization (qPCR) & $\ldots$ & $\ldots$ & $<0.01$ \\
Aflatoxin accumulation & $\ldots$ &
\end{tabular}

${ }^{\mathrm{x}}$ In vitro experiments were replicated four times using field materials grown in New York for 3 years. Field inoculation experiments were replicated three times in a randomized complete blocks design for 3 years. For all the experiments, except for silk latent period, there was a significant effect of the random variation due to the interaction of year by inbred line.

${ }^{y}$ qPCR $=$ quantitative polymerase chain reaction.

${ }^{\mathrm{z}}$ In vitro experiments on kernels were conducted on 3-week-old kernels. Field evaluation of components of resistance was conducted on mature kernels; $\mathrm{ns}=$ not analyzed statistically because all developing kernels sporulated on the same day. lines were not discernible by Tukey's test $(\alpha=0.05)$. For field inoculation assays, significant differences were found for silk and kernel colonization among inbred lines for each of the 3 years of study. As indicated above and by Spearman correlations, the ranking of lines varied from year to year, except for colonization on silks, colonization in mature kernels, and aflatoxin accumulation in mature kernels (Supplementary Tables 1 and 2).

Components of silk resistance (year by year). Significant differences were found for in vitro and field-inoculated components of silk resistance within multiple years (Table 5; Supplementary Tables 3 and 4). None of the components of silk resistance was significantly correlated with aflatoxin accumulation on kernels. In addition, the components of resistance in 2009 evaluated in vitro were significantly correlated with each other, as were SP in 2009 and IF in 2007. Rankings of LP evaluated in vitro from greenhouse materials were negatively correlated with IF and SP in 2009 (as expected) but positively correlated with colonization in 2008 (unexpected).

Components of kernel resistance (year by year). Developing kernels of inbred lines were significantly different for SP and colonization in every year the experiments were conducted in vitro (Table 5; Supplementary Table 5). Field inoculation experiments every year indicated significant differences for colonization and aflatoxin accumulation (Table 5; Supplementary Table 6). In vitro inoculations of developing kernels in four

TABLE 4. Pairwise Pearson correlations among components of kernel resistance to Aspergillus flavus and other maize characteristics in a panel of diverse maize inbred lines

\begin{tabular}{|c|c|c|c|c|}
\hline \multirow[b]{2}{*}{ Characteristics } & \multicolumn{2}{|c|}{ Field $^{\mathrm{x}}$} & \multicolumn{2}{|c|}{ In vitro ${ }^{x}$} \\
\hline & Aflatoxin & Colonization & Colonization & Sporulation \\
\hline \multicolumn{5}{|l|}{ Field } \\
\hline Colonization & $0.70 * * *$ & $\ldots$ & $\ldots$ & $\ldots$ \\
\hline \multicolumn{5}{|l|}{ In vitro } \\
\hline Colonization & 0.02 & -0.16 & $\ldots$ & $\ldots$ \\
\hline Sporulation & 0.06 & -0.01 & 0.00 & $\ldots$ \\
\hline \multicolumn{5}{|l|}{ Flowering $\mathrm{y}$} \\
\hline Days to silk & $-0.61^{*}$ & -0.47 & -0.04 & $-0.60 *$ \\
\hline \multicolumn{5}{|l|}{ Kernel traits $\mathrm{z}$} \\
\hline Moisture & -0.03 & -0.02 & 0.33 & $-0.53 *$ \\
\hline Protein & -0.45 & -0.21 & -0.38 & 0.39 \\
\hline Fat & -0.25 & -0.17 & 0.03 & 0.27 \\
\hline Fiber & $-0.68 * *$ & -0.47 & -0.07 & 0.03 \\
\hline Ash & $-0.57^{*}$ & -0.50 & 0.03 & 0.26 \\
\hline Carbohydrate & $0.52^{*}$ & 0.27 & 0.23 & -0.38 \\
\hline Seed weight & $0.57 *$ & 0.46 & 0.14 & -0.41 \\
\hline Endosperm (\%) & 0.12 & 0.09 & -0.05 & 0.15 \\
\hline
\end{tabular}

TABLE 3. Pairwise Pearson correlations among components of silk resistance to Aspergillus flavus in a panel of diverse maize inbred lines ${ }^{\mathrm{y}}$

\begin{tabular}{|c|c|c|c|c|c|}
\hline \multirow[b]{2}{*}{ Characteristics } & \multicolumn{2}{|c|}{ Field } & \multicolumn{3}{|c|}{ In vitro } \\
\hline & Aflatoxin & Colonization & Latent period & Infection frequency & Sporulation \\
\hline \multicolumn{6}{|l|}{ Field } \\
\hline Colonization & 0.22 & $\ldots$ & $\ldots$ & $\ldots$ & $\ldots$ \\
\hline In vitro & & & $\ldots$ & $\ldots$ & \\
\hline Latent period & 0.23 & -0.17 & $\ldots$ & $\ldots$ & $\ldots$ \\
\hline Infection frequency & -0.12 & -0.29 & -0.19 & $\ldots$ & $\ldots$ \\
\hline Sporulation & -0.28 & -0.16 & -0.37 & $0.63 * *$ & $\ldots$ \\
\hline \multicolumn{6}{|l|}{ Flowering time ${ }^{\mathrm{z}}$} \\
\hline Days to silk (field) & $-0.61 *$ & -0.44 & 0.32 & 0.14 & 0.40 \\
\hline
\end{tabular}

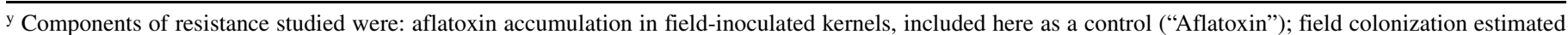
by quantitative polymerase chain reaction ("Colonization"); days before sporulation in vitro ("Latent period"); percentage of silks showing sporulation in vitro ("Infection frequency"); and extent of sporulation in vitro ("Sporulation"); * and ** indicate significant correlations at $P<0.05$ and 0.01 , respectively.

z According to Buckler et al. (6). 
experiments indicated that there were no differences for LP or IF among the inbreds tested in this study. Aflatoxin accumulation and colonization after field inoculations were generally correlated, with some exceptions with the 2010 values. Field-inoculated aflatoxin accumulation in 2008 was significantly correlated with in-vitro-inoculated SP in $2008(0.59, P=0.026)$. In-vitroinoculated ranks of SP in 2008 were also correlated with fieldinoculated colonization in 2008. However, in-vitro-inoculated SP rankings in 2008 were negatively correlated with in-vitroinoculated colonization in $2008\left(-0.45^{*}, P=0.047\right)$. Colonization for in vitro inoculations with greenhouse materials was correlated with SP from the same materials.

\section{DISCUSSION}

Despite the substantial genotype-environment interaction, there was clear evidence of resistance to silk colonization from field inoculations. We found significant differences among lines across 3 years of field-inoculated experiments for three components of resistance: colonization of silk and kernel and aflatoxin accumulation. A strong correlation $(0.70, P=0.0008)$ between aflatoxin accumulation and colonization in field experiments confirmed our previous results, in which the two traits were significantly correlated $(0.85, P<0.0001)$ in the first year of this study $(21)$. Although aflatoxin accumulation and silk colonization were not correlated, it is important to keep in mind that our aflatoxin determination was done on kernels that were inoculated in the silk and the side of the ear at the same time, so that silk resistance would not be expected to reduce kernel infection or aflatoxin accumulation in the kernels. We have demonstrated the existence of silk resistance, which presumably has an important role in natural aflatoxin accumulation. It will be important to verify in future studies that resistance expressed in silk contributes to fieldlevel resistance under natural inoculum or silk-channel inoculation.

Significant year-inbred interactions for every component of resistance studied indicated that the environment in which the plant is grown has a large effect on the expression of resistance. No component of resistance was stable across environments.
Strong variation among years for in vitro traits sharply contrasted with the reproducibility within any given year (Table 5). In vitro experiments kept the plants in a homogeneous environment and we still found significant variation from year to year, indicating that the environment in which the plant is grown has a strong influence on the A. flavus-maize interaction. In addition, a significant negative correlation of flowering time with aflatoxin accumulation was observed. The later-maturing genotypes were inoculated later in the season, so the differences be due to environmental variation toward the end of the season, or they could reflect physiological differences among genotypes differing in maturity group.

We did not see a correlation between our in vitro results and aflatoxin accumulation in the field. It is important to consider that, in this study, we used developing kernels rather than mature kernels, as has been used by previous authors (5). Our results indicate that, when designing in vitro studies with developing kernels, the environment in which the kernels are grown is an important source of variation. In other experiments with mature kernels, we have found that the growth environment also affects the levels of resistance (S. K. Mutiga and R. J. Nelson, unpublished data). It is known that growth environment influences kernel composition; for example, soil nitrogen levels in the plant growth environment influence maize kernel composition $(23,32)$.

To explore genetically determined kernel composition as a possible factor influencing A. flavus colonization, we chose to analyze our data in relation to available data on kernel traits for some of the genotypes in our study. Flint-Garcia et al. (12) had determined kernel composition and seed characteristics in a panel that contained 19 of the inbreds used in this study. From this data set, we used the reported least square means calculated by the authors from 2 years of experiments in Puerto Rico. Significant correlations of aflatoxin content with fiber, ash, carbohydrates, and seed weight suggests that kernel composition traits should be further explored in the future. Fiber and ash content may correlate with the thickness of pericarp and aleurone layers, reflecting barriers to fungal ingress. Cardwell and Henry (8) have previously suggested a relationship between large kernel size (often selected in breeding programs to increase yield) and susceptibility

TABLE 5. Estimates of significance ( $P$ values for analysis of variance) for components of resistance to Aspergillus flavus of a set of diverse maize inbred lines by year of study

\begin{tabular}{|c|c|c|c|c|c|c|}
\hline \multirow[b]{2}{*}{ Resistance component } & \multirow[b]{2}{*}{ Year } & \multirow[b]{2}{*}{ Source of material } & \multicolumn{2}{|c|}{ Silk } & \multicolumn{2}{|c|}{ Kernel } \\
\hline & & & $P$ & $n$ & $P$ & $n$ \\
\hline \multicolumn{7}{|l|}{ In vitro inoculation } \\
\hline \multirow[t]{3}{*}{ Latent period } & 2007 & Field, New York & $0.0129^{\mathrm{z}}$ & 19 & $\mathrm{~ns}$ & 19 \\
\hline & 2008 & Field, New York & 0.4269 & 21 & $\mathrm{~ns}$ & 25 \\
\hline & 2009 & Field, New York & 0.0109 & 20 & ns & 26 \\
\hline Infection frequency & 2007 & Field, New York & 0.0001 & 12 & ns & 12 \\
\hline \multirow[t]{4}{*}{ Sporulation } & 2007 & Field, New York & 0.0116 & 17 & $<0.0001$ & 15 \\
\hline & 2007 & Greenhouse & $0.0100^{z}$ & 7 & $<0.0001$ & 7 \\
\hline & 2008 & Field, New York & 0.4934 & 21 & $<0.0001$ & 25 \\
\hline & 2009 & Field, New York & $<0.0001$ & 20 & $<0.0001$ & 26 \\
\hline \multirow[t]{2}{*}{ Colonization } & 2007 & Greenhouse & $<0.0001$ & 7 & $<0.0001$ & 7 \\
\hline & 2008 & Field, New York & $<0.0001$ & 19 & $<0.0001$ & 25 \\
\hline \multirow[t]{3}{*}{ Aflatoxin } & 2008 & Field, Mississippi & $\ldots$ & $\ldots$ & $<0.0001$ & 18 \\
\hline & 2009 & Field, Mississippi & $\ldots$ & $\ldots$ & $<0.0001$ & 23 \\
\hline & 2010 & Field, Mississippi & $\ldots$ & $\ldots$ & 0.0409 & 25 \\
\hline
\end{tabular}

y Colonization estimated by quantitative polymerase chain reaction; $\mathrm{ns}=$ not analyzed statistically because all kernels sporulated on the same day.

${ }^{\mathrm{z}}$ Inbred lines were not significantly different for multiple comparisons using Tukey’s test. 
to A. flavus. Our results suggest that size (reflected by seed weight) and kernel composition affect the A. flavus-maize interaction.

Another interesting significant negative correlation was found between kernel SP from in vitro assays (measured using fresh, immature kernels) and kernel moisture (measured using dry, mature kernels). This suggests a testable hypothesis that structural features that impede water loss in mature kernels also impede pathogen ingress. Supporting this hypothesis is the recent finding that $F$. verticillioides enters the kernel through the stylar canal, and that stylar canal apertures vary between resistant and susceptible maize lines (11). In preliminary experiments conducted using scanning electron microscopy, we have characterized the stylar canal on mature kernels from a subset of the diverse lines reported here. Although our limited measurements of length and width did not correlate with aflatoxin accumulation levels, we found a striking variation in the shapes, sizes, and locations of the stylar canal. This variation of a developmental aperture located on the top of the kernel, the formation of which is coincident with $A$. flavus infection of the kernels in the field, could be important in understanding the infection process. The microscopic analyses of the initial infection of A. flavus and maize kernels were conducted a few decades ago and no recent detailed infection study such as the one conducted for $F$. verticillioides has been reported.

In this study, compelling evidence is presented that, in addition to resistance to aflatoxin accumulation, there is variation in maize germplasm for susceptibility to silk and kernel colonization. Strong and consistent correlations of aflatoxin levels with $A$. flavus biomass indicate that part of the resistance is due to mechanisms that limit the colonization of maize kernels in the field. We found that the environment in which the plants were grown strongly influenced in vitro inoculation assays for $A$. flavus. We did not identify a component of resistance that was not environmentally affected but we found that kernel characteristics and flowering time were significantly associated with resistance to aflatoxin accumulation. Many of the lines used in this study are part of maize diversity sets or other large public efforts to characterize quantitative traits in maize, and our results could provide a guide for future hypothesis testing using these resources $(13,20)$.

\section{ACKNOWLEDGMENTS}

This work was funded, in part, by The McKnight Foundation. Planting, inoculation, and phenotype evaluations in Mississippi were conducted with the help of all the personnel of the Corn Host Plant Resistance Research Unit of the United States Department of Agriculture-Agricultural Research Service. We thank M. Warburton for hosting S. X. Mideros in Mississippi for three summers and graduate and undergraduate students at R. Nelson's Maize Disease Resistance Lab for help with in vitro inoculations in New York.

\section{LITERATURE CITED}

1. Balconi, C., Motto, M., Mazzinelli, G., and Berardo, N. 2010. Ear secondary traits related to aflatoxin accumulation in commercial maize hybrids under artificial field inoculation. World Mycotoxin J. 3:239-250.

2. Baumgarten, A. M., Suresh, J., May, G., and Phillips, R. L. 2007. Mapping QTLs contributing to Ustilago maydis resistance in specific plant tissues of maize. Theor. Appl. Genet. 114:1229-38.

3. Betrán, F. J., Isakeit, T., and Odvody, G. 2002. Aflatoxin accumulation of white and yellow maize inbreds in diallel crosses. Crop Sci. 42:18941901 .

4. Brooks, T., Williams, W. P., Windham, G. L., Willcox, M. C., and Abbas, H. K. 2005. Quantitative trait loci contributing resistance to aflatoxin accumulation in the maize inbred Mp313E. Crop Sci. 45:171-174.

5. Brown, R. L., Chen, Z. Y., Cleveland, T. E., and Russin, J. S. 1999. Advances in the development of host resistance in corn to aflatoxin contamination by Aspergillus flavus. Phytopathology 89:113-117.

6. Buckler, E. S., Holland, J. B., Bradbury, P. J., Acharya, C. B., Brown, P. J., Browne, C., Ersoz, E., Flint-Garcia, S., Garcia, A., Glaubitz, J. C.,
Goodman, M. M., Harjes, C., Guill, K., Kroon, D. E., Larsson, S., Lepak, N. K., Li, H., Mitchell, S. E., Pressoir, G., Peiffer, J. A., Rosas, M. O., Rocheford, T. R., Romay, M. C., Romero, S., Salvo, S., Sanchez Villeda, H., da Silva, H. S., Sun, Q., Tian, F., Upadyayula, N., Ware, D., Yates, H., Yu, J., Zhang, Z., Kresovich, S., and McMullen, M. D. 2009. The genetic architecture of maize flowering time. Science 325:714-718.

7. Busboom, K. N., and White, D. G. 2004. Inheritance of resistance to aflatoxin production and Aspergillus ear rot of corn from the cross of inbreds B73 and Oh516. Phytopathology 94:1107-1115.

8. Cardwell, K. F., and Henry, S. H. 2004. Risk of exposure to and mitigation of effect of aflatoxin on human health: A West African example. Toxin Rev. 23:217-247.

9. Chen, Z. Y., Brown, R. L., Damann, K. E., and Cleveland, T. E. 2010. PR10 expression in maize and its effect on host resistance against Aspergillus flavus infection and aflatoxin production. Mol. Plant Pathol. 11:69-81.

10. Chung, C. L., Longfellow, J. M., Walsh, E. K., Kerdieh, Z., Van Esbroeck, G., Balint-Kurti, P., and Nelson, R. J. 2010. Resistance loci affecting distinct stages of fungal pathogenesis: use of introgression lines for QTL mapping and characterization in the maize-Setosphaeria turcica pathosystem. BMC Plant Biol. 10:103.

11. Duncan, K., and Howard, R. 2010. Biology of maize kernel infection by Fusarium verticillioides. Mol. Plant-Microbe Interact. 23:6-16.

12. Flint-Garcia, S. A., Bodnar, A. L., and Scott, M. P. 2009. Wide variability in kernel composition, seed characteristics, and zein profiles among diverse maize inbreds, landraces, and teosinte. Theor. Appl. Genet. 119:1129-1142.

13. Flint-Garcia, S. A., Thuillet, A. C., Yu, J., Pressoir, G., Romero, S. M., Mitchell, S. E., Doebley, J., Kresovich, S., Goodman, M. M., and Buckler, E. S. 2005. Maize association population: a high-resolution platform for quantitative trait locus dissection. Plant J. 44:1054-1064.

14. Gembeh, S. V., Brown, R. L., Grimm, C., and Cleveland, T. E. 2001. Identification of chemical components of corn kernel pericarp wax associated with resistance to Aspergillus flavus infection and aflatoxin production. J. Agric. Food Chem. 49:4635-4641.

15. Gorman, D. P., and Kang, M. S. 1991. Preharvest aflatoxin contamination in maize-resistance and genetics. Plant Breed. 107:1-10.

16. Groopman, J. D., Kensler, T. W., and Wild, C. P. 2008. Protective interventions to prevent aflatoxin-induced carcinogenesis in developing countries. Annu. Rev. Public Health 29:187-203.

17. Horn, B. W., Moore, G. G., and Carbone, I. 2009. Sexual reproduction in Aspergillus flavus. Mycologia 101:423-429.

18. Kump, K. L., Bradbury, P. J., Wisser, R. J., Buckler, E. S., Belcher, A. R., Oropeza-Rosas, M. A., Zwonitzer, J. C., Kresovich, S., McMullen, M. D., Ware, D., Balint-Kurti, P. J., and Holland, J. B. 2011. Genome-wide association study of quantitative resistance to southern leaf blight in the maize nested association mapping population. Nat. Genet. 43:163-168.

19. Madden, L. V., Knoke, J. K., and Louie, R. 1982. Considerations for the use of multiple comparison procedures in phytopathological investigations. Phytopathology 72:1015-1017.

20. McMullen, M. D., Kresovich, S., Villeda, H. S., Bradbury, P., Li, H., Sun, Q., Flint-Garcia, S., Thornsberry, J., Acharya, C., Bottoms, C., Brown, P., Browne, C., Eller, M., Guill, K., Harjes, C., Kroon, D., Lepak, N., Mitchell, S. E., Peterson, B., Pressoir, G., Romero, S., Oropeza Rosas, M., Salvo, S., Yates, H., Hanson, M., Jones, E., Smith, S., Glaubitz, J. C., Goodman, M., Ware, D., Holland, J. B., and Buckler, E. S. 2009. Genetic properties of the maize nested association mapping population. Science 325:737-740.

21. Mideros, S. X., Windham, G. L., Williams, W. P., and Nelson, R. J. 2009. Aspergillus flavus biomass in maize estimated by quantitative real-time polymerase chain reaction is strongly correlated with aflatoxin concentration. Plant Dis. 93:1163-1170.

22. Munkvold, G. P. 2003. Cultural and genetic approaches to managing mycotoxins in maize. Annu. Rev. Phytopathol. 41:99-116.

23. Oikeh, S. O., Kling, J. G., and Okoruwa, A. E. 1998. Nitrogen fertilizer management effects on maize grain quality in the west African moist savanna. Crop Sci. 38.

24. Parlevliet, J. E. 1979. Components of resistance that reduce the rate of epidemic development. Annu. Rev. Phytopathol. 17:203-222.

25. Pechanova, O., Pechan, T., Williams, W. P., and Luthe, D. S. 2011. Proteomic analysis of the maize rachis: potential roles of constitutive and induced proteins in resistance to Aspergillus flavus infection and aflatoxin accumulation. Proteomics 11:114-127.

26. Peethambaran, B., Hawkins, L. K., Windham, G. L., Williams, W. P., and Luthe, D. S. 2009. Anti-fungal activity of maize silk proteins and role of chitinases in Aspergillus flavus resistance. Toxin Rev. 29:27-39.

27. Poland, J. A., Balint-Kurti, P. J., Wisser, R. J., Pratt, R. C., and Nelson, R. J. 2009. Shades of gray: the world of quantitative disease resistance. Trends Plant Sci. 14:21-29.

28. Poland, J. A., Bradbury, P. J., Buckler, E. S., and Nelson, R. J. 2011. 
Genome-wide nested association mapping of quantitative resistance to northern leaf blight in maize. Proc. Natl. Acad. Sci. USA 108:6893-6898.

29. Reid, L. M., Mather, D. E., Bolton, A. T., and Hamilton, R. I. 1994. Evidence for a gene for silk resistance to Fusarium graminearum ear rot of maize. J. Hered. 85:118-121.

30. Smart, M. G., Wicklow, D. T., and Caldwell, R. W. 1990. Pathogenesis in Aspergillus ear rot of maize: light-microscopy of fungal spread from wounds. Phytopathology 80:1287-1294.

31. St Clair, D. A. 2010. Quantitative disease resistance and quantitative resistance loci in breeding. Annu. Rev. Phytopathol. 48:247-268.

32. Tsai, C. Y., Dweikat, I., Huber, D. M., and Warren, H. L. 1992. Interrelationship of nitrogen nutrition with maize (Zea mays) grain yield, nitrogen use efficiency and grain quality. J. Sci. Food Agric. 58:1-8.

33. Warburton, M. L., Brooks, T. D., Krakowsky, M. D., Shan, X., Windham, G. L., and Williams, W. P. 2009. Identification and mapping of new sources of resistance to aflatoxin accumulation in maize. Crop Sci. 49:1403-1408.
34. Warburton, M. L., Brooks, T. D., Windham, G. L., and Williams, W. P. 2011. Identification of novel QTL contributing resistance to aflatoxin accumulation in maize. Mol. Breed. 27:491-499.

35. Wild, C. P., and Turner, P. C. 2002. The toxicology of aflatoxins as a basis for public health decisions. Mutagenesis 17:471-481.

36. Williams, W. P. 2006. Breeding for resistance to aflatoxin accumulation in maize. Mycotoxin Res. 22:27-32.

37. Williams, W. P., Krakowsky, M., Windham, G., Balint-Kurti, P., Hawkins, L., and Henry, W. B. 2008. Identifying maize germplasm with resistance to aflatoxin accumulation. Toxin Rev. 27:319-345.

38. Williams, W. P., and Windham, G. L. 2006. Registration of maize germplasm line Mp717. Crop Sci. 46:1407-1408.

39. Williams, W. P., Windham, G. L., and Buckley, P. M. 2008. Diallel analysis of aflatoxin accumulation in maize. Crop Sci. 48:134-138.

40. Windham, G. L., Williams, W. P., Hawkins, L. K., and Brooks, T. D. 2009. Effect of Aspergillus flavus inoculation methods and environmental conditions on aflatoxin accumulation in corn hybrids. Toxin Rev. 28:70-78. 